\title{
EL SENTIDO TEOLÓGICO DE UNA ESPIRITUALIDAD EN CAMINO: LA ESPIRITUALIDAD DE LA LIBERACIÓN ENTRE PUEBLA Y SANTO DOMINGO ${ }^{1}$
}

\section{Theological Meaning of a Spirituality on the Way: Spirituality of Liberation Theology between Puebla and Santo Domingo}

\section{O sentido teológico de uma espiritualidade em caminho: a espiritualidade da libertaçáo entre Puebla e Santo Domingo}

\author{
Jairo Gómez Díaz* \\ Adriana Alejandra Hoyos Camacho**
}

1 El presente artículo es resultado del proyecto de investigación «Espiritualidad Cristiana en América Latina: evolución de sus expresiones desde Puebla hasta Santo Domingo» del grupo de investigación Academia de la Pontificia Universidad Javeriana. La investigación inició en marzo del 2014 y culminó en octubre de 2015.

Magíster en Teología (2015), Pontificia Universidad Javeriana, Bogotá, Colombia. Miembro del grupo de investigación Academia de la misma universidad. C.C. 91283 728. orcid.org/0000-0001-7244-4354. Correo electrónico: jairo1971@hotmail.com

* Magistra en Teología (2008), Pontificia Universidad Javeriana, Bogotá, Colombia. Docente investigadora, Pontificia Universidad Javeriana. Miembro del grupo de investigación Academia de la misma universidad. C.C. 51917739. orcid.org/00000003-2407-826x. Correo electrónico: aahoyos@javeriana.edu.co

Artículo recibido el 18 enero de 2016 y aprobado para su publicación el 1 marzo de 2016. 


\author{
Rosana Elena Navarro Sánchez*** \\ Hermann Rodríguez Osorio, S.J.**** \\ Orlando Solano Pinzón***** \\ Jorge ZuREK LEQUERICA******
}

\title{
Resumen
}

Este escrito pretende ilustrar la forma en que se vigorizó la reflexión sobre Espiritualidad de la Liberación durante la etapa comprendida entre la III Conferencia General del Episcopado, realizada en Puebla, y la IV Conferencia realizada en Santo Domingo. Es el resultado de una investigación elaborada desde la propuesta del método en teología de Bernard Lonergan, el cual facilitó la aproximación a la producción escrita sobre espiritualidad en dicho periodo. La investigación constató que la espiritualidad que emergió como fundamento de la Teología de la Liberación, lejos de desaparecer o desvirtuarse, debido a las profundas críticas suscitadas en el medio, se fue consolidando a partir de sus referentes teológicos fundamentales. Entre ellos, la encarnación y el seguimiento de Jesús.

*** Doctora en Teología (2016), Pontificia Universidad Javeriana, Bogotá, Colombia. Magistra en Teología (2007). Magistra en Educación (1992) de la misma Universidad. Docente investigadora, Pontificia Universidad Javeriana. Miembro del grupo de investigación Academia de la misma universidad. C.C. 20.472.290. orcid.org/00000003-0322-669X. Correo electrónico: rosana.navarro@javeriana.edu.co

**** Doctor en Teología (2000), Universidad Pontificia de Comillas, Madrid, España. Magister en Pscicología Comunitaria (1993), Pontificia Universidad Javeriana, Bogotá, Colombia. Docente investigador de la Pontificia Universidad Javeriana. Miembro del grupo de investigación Academia de la misma universidad. C.C. 79.147.484. orcid. org/0000-0001-8302-4945. Correo electrónico: hermann.rodriguez@javeriana.edu.co

**e** Doctor en Teología (2014), Pontificia Uniersidad Javeriana. Docente investigador, Pontificia Universidad Javeriana. Miembro del grupo Academia de la misma universidad. C.C. 13.515.663. orcid.org/0000-0003-4446-626X Correo electrónico: o.solano@ javeriana.edu.co

${ }^{* x * * * *}$ Doctor en Teología (2010). The University of Toronto. Docente investigador de la Pontificia Universidad Javeriana. Miembro del grupo Academia de la misma universidad. C.C. 79281442 orcid.org/0000-0002-0168-9757 Correo electrónico: jzurek@javeriana. edu.co 


\title{
Palabras clave
}

Espiritualidad, Liberación, Encarnación, Seguimiento, Sentido Teológico.

\begin{abstract}
The article aims to illustrate the way in which the reflection about the Spirituality of Liberation was strengthened during the period of time that goes from the Third General Conference of the Latin American Episcopate to the Fourth one -which took place in Puebla and Santo Domingo respectively. The research is conducted following Bernard Lonergan's Method in Theology, which facilitated the approach to the writings about spirituality in that particular period. The research confirmed that the spirituality that appeared as a basis for Liberation Theology, far from disappearing or losing value due to the strong criticism voiced, was strengthened because of its fundamental theological sources such as the Incarnation of Jesus and Discipleship.
\end{abstract}

\section{Keywords}

Spirituality, Liberation, Incarnation, Discipleship, Theological Meaning.

\section{Resumo}

Este escrito pretende ilustrar a forma com que se fortaleceu a reflexão sobre a Espiritualidade da Libertação durante a etapa compreendida entre a III Conferência Geral do Episcopado, realizada em Puebla, e a IV Conferência, realizada em Santo Domingo. É o resultado de uma pesquisa elaborada a partir da proposta do método em teologia de Bernard Lonergan, o qual facilitou a aproximação à produção escrita sobre espiritualidade em tal período. A investigação constatou que a espiritualidade que emergiu como fundamento da Teologia da Libertação, longe de desaparecer ou desvirtuar-se, devido às profundas críticas suscitadas nos meios, foi consolidando-se a partir de seus referentes teológicos fundamentais. Entre elos, a encarnação e o seguimento de Jesus.

\section{Palavras-chave}

Espiritualidade, Libertação, Encarnação, Seguimento, Sentido Teológico. 


\section{INTRODUCCIÓN}

La investigación sobre la evolución de las expresiones de la Espiritualidad de la Liberación en América Latina fue pensada en cuatro etapas. La primera etapa estudió el período entre la Segunda Conferencia General del Episcopado que ocurrió en Medellín (1968) y la Tercera Conferencia que tuvo lugar en la ciudad de Puebla (1979). El presente artículo corresponde a una segunda etapa de este proceso y estudia lo que sucedió durante los años transcurridos entre la Tercera Conferencia y la Cuarta Conferencia ${ }^{2}$, que tuvo como sede la ciudad de Santo Domingo, en el año 1992. Están pendientes de su desarrollo la etapa tercera (1992-2007) y la cuarta, esta última estudiará el desarrollo de la Espiritualidad a partir del año 2007 hasta el año en el que se finalice la investigación.

Tal como presentamos en el artículo sobre la primera etapa de esta investigación (Estupiñán, Hoyos, Navarro, Rodríguez, Solano \& Surek, 2013) en los ańos setenta hubo un renacer de la esperanza de renovación pastoral e institucional de la Iglesia latinoamericana; fue el fruto de una manera de vivenciar el encuentro con Dios en los pobres y los oprimidos de nuestro continente. Por otra parte, apareció con fuerza la espiritualidad como fuente de una nueva forma de hacer teología. En la década de los ochenta se consolidaron esos procesos de renovación de la Espiritualidad Cristiana y latinoamericana. Este período dio origen a una enorme producción teológica que sistematiza nuevos modos de concebir la espiritualidad y sus implicaciones en el ámbito de la reflexión teológica y en el quehacer de la Iglesia.

El presente artículo quiere contribuir en la sistematización de los nuevos aportes surgidos en la reflexión teológica latinoamericana, particularmente en torno a la Espiritualidad de la Liberación, durante los años 1979 a 1992, período comprendido entre las dos Conferencias Generales del Episcopado Latinoamericano, celebradas en Puebla y Santo Domingo. Para tal efecto, en un primer momento se hace un breve acercamiento al contexto, posteriormente se abordan los avances sistemáticos junto con los personajes más representativos del período investigado. A continuación, se explicitan

2 La referencia a las Conferencias Generales del Episcopado dentro de nuestra investigación tiene como único objeto la delimitación del período a investigar. 
los rasgos de la espiritualidad. Por último, se da cuenta del sentido teológico que subyace a los rasgos ya mencionados y se cierra con una conclusión.

\section{CONTEXTO}

A partir del Concilio Ecuménico Vaticano II, y su desarrollo en América Latina a través de la Segunda Conferencia General del Episcopado, se produce una renovación espiritual, teológica, pastoral e institucional de la Iglesia del continente. Desde finales de los años sesenta y la década de los setenta hay un cambio de paradigma en el que la experiencia espiritual se convierte en compromiso con los procesos de liberación histórica de los empobrecidos como lugar privilegiado de encuentro con Dios.

Durante la década de los ochenta se dio una progresiva consolidación de la Teología y de la Espiritualidad de la Liberación. Hubo una enorme producción intelectual en este campo y se fortaleció una propuesta novedosa en el ámbito de la teología a nivel mundial. A finales de esta década, en medio de fuertes crisis económicas, «el aumento de la pobreza en términos absolutos y relativos y la vulnerabilidad de los mercados nacionales frente a los impactos recesivos externos» (Lepre, 2008, p. 1) comienza a imponerse el neoliberalismo en buena parte de los países de América Latina ${ }^{3}$. Hay múltiples dificultades que impiden el crecimiento económico en la región y la pobreza se hace más cruda para millones de latinoamericanos (Olivieri, 1984, p. 188).

Los movimientos que abogaban por la reivindicación de la libertad, de la justicia social y de mejores condiciones de vida, encarnaron, en un primer momento, el dinamismo liberador que, posteriormente, fue interpretado desde la fe, particularmente desde el Éxodo, como paradigma de liberación del pueblo de Israel. A partir de esa actualización de la narrativa bíblica se establecieron unas analogías de proporción entre la realidad de esclavitud,

3 Esta incursión del neoliberalismo coincide con la caída del muro de Berlín y del afianzamiento norteamericano, en tanto que en América Latina las tensiones y conflictos de los gobiernos militares van en aumento. 
vivida por el pueblo de Israel en Egipto, y las ansias de liberación de los pueblos latinoamericanos. Esa lectura de la realidad permitió re-significar la experiencia de fe en el encuentro con Dios en el pobre y sus anhelos legítimos de liberación. Esta interpretación se convirtió en fuente de inspiración para alentar, desde la dinámica del Espíritu, la lucha por la liberación política, económica y social que exigía la dolorosa realidad.

Esta fue una etapa de reflexión teológica y de construcción de una propuesta nueva en la que la Espiritualidad de la Liberación fue perfilando sus rasgos y sus dinamismos particulares. Como fruto del diálogo entre el Evangelio y los pobres, el quehacer teológico latinoamericano replanteó sus tratados, consolidando así su pensamiento bajo una síntesis propuesta en Mysterium Liberationis I (Ellacuría \& Sobrino, 1990) ${ }^{4}$. Este proceso de fortalecimiento de la reflexión teológica latinoamericana produjo una enorme cantidad de libros y artículos sobre Espiritualidad de la Liberación, que intentaban recoger la necesaria fidelidad al dinamismo del Espíritu, en un contexto en el que la experiencia de Dios estaba íntimamente ligada al encuentro con el pobre y su causa de liberación (Jaén, 1987).

La Congregación para la Doctrina de la Fe se pronunció sobre este proceso con la publicación de dos instrucciones. La primera, Libertatis Nuntius. Instrucción sobre algunos aspectos de la Teología de la Liberación, publicada en 1984, recoge serios cuestionamientos y señala riesgos que puede tener la Teología de la Liberación. Igualmente, apunta a las posibles desviaciones que pueden darse en el desarrollo de dicha teología. La segunda, Libertatis Conscientia. Instrucción sobre Libertad Cristiana y Liberación, publicada en 1986, fue una exposición más propositiva, que reconocía las peculiaridades de una teología apoyada en el dinamismo de la liberación. Entre las reacciones de los teólogos de la liberación destaca la de Camilo Maccise (1987, p. 48) para quien estas dos instrucciones ayudaron a crecer al movimiento de liberación sin que fuera su intención fundamental. ${ }^{5}$

4 En 1990 Jon Sobrino e Ignacio Ellacuría recogieron en una exposición histórica y sistemática los conceptos fundamentales de la Teología de la Liberación. A través de cincuenta trabajos, cuyos autores son los principales representantes de esta teología, se pretendió ofrecer un recorrido por su historia, su método y sus contenidos sistemáticos.

5 Esta afirmación de Maccise obedece a que dichas instrucciones permitieron reafirmar algunos puntos defendidos por la Teología de la Liberación: que ella surge de la realidad 
Particularmente la realidad del pobre, como lugar privilegiado y preferencial de encuentro con Dios, y la necesidad de una liberación integral, se consolidaron alimentadas por el impulso de una experiencia espiritual.

\section{AVANCES SISTEMÁTICOS}

Gustavo Gutiérrez (1984; 1992; 1975), Jon Sobrino (1990; 1979-1980; 1984; 1982; 1983), Segundo Galilea (1982), Néstor Jaén (1987), Pedro Casaldáliga y José María Vigil (1992), especialmente, recogieron en sus escritos los anhelos de liberación presentes en las comunidades eclesiales de base y en otras organizaciones populares y eclesiales. Contribuyeron en la comprensión global de la Espiritualidad de la Liberación promoviendo la reordenación de los ejes fundamentales de la vida cristiana, cuya fuente es la experiencia de Dios en el encuentro con el pobre y su causa de liberación.

\subsection{Gustavo Gutiérrez}

Gutiérrez (1984) sistematiza en su escrito Beber en su propio pozo, la experiencia previa de gestación de la Espiritualidad de la Liberación, que fue sugerida brevemente en el libro de Teología de la Liberación. Perspectivas en el año 1971. Su comprensión de la espiritualidad está elaborada desde el misterio de la Encarnación, referente que le da un toque particular a su forma de acercarse a la experiencia espiritual que hacen las comunidades eclesiales con las que comparte la fe. Además, hace posible encuadrar la propuesta desde una clara dinámica de seguimiento de Jesús.

La particularidad de la Espiritualidad de la Liberación, que viven estas comunidades eclesiales con las que trabaja Gutiérrez en zonas deprimidas del Perú radica en que se trata de comunidades que viven situaciones de

colectiva de opresión y de la aspiración a la liberación; que ella está vinculada a un tema bíblico capital, el de la liberación y la libertad; que no se puede ignorar y poner a un lado la situación de miseria dramática que ha interpelado a estos teólogos; y que no se aprueban las actitudes y acciones de los indiferentes y de los que contribuyen al mantenimiento de la miseria de los pueblos. 
soledad y desierto, imágenes de lo que el pueblo de Israel vivió en su proceso de liberación de la esclavitud a la que los sometieron los egipcios. El pueblo soporta, además de situaciones de marginación, la pobreza e injusticia que les obligan a vivir una relación dialógica entre conversión y solidaridad, debido a que «la vivencia de la solidaridad exige la conversión, punto de partida de todo seguimiento de Jesús» (Gutiérrez, 1984, p. 142).

Por otra parte, la experiencia de la gratuidad que se puede vivir en estas comunidades creyentes populares contrasta con las exigencias de la eficacia que exige nuestra caridad (Gutiérrez, 1984, p. 164). De modo semejante aparece el contraste entre la alegría en medio del sufrimiento. Una alegría que brota del don ya recibido en Cristo y todavía esperado en su realización definitiva que se expresa en el presente a pesar de la dureza y las tensiones de la lucha por la construcción de una sociedad más humana y más justa.

Otra relación dialógica que descubre Gutiérrez en medio de las comunidades eclesiales es la de la infancia espiritual y la pobreza real, porque «solo desde la infancia espiritual es posible comprometerse verdaderamente con los pobres y oprimidos de nuestro subcontinente» (Gutiérrez, 1984, p. 190). Igualmente, aparece la relación entre comunidad y soledad, en cuanto, «la vida en comunidad acoge y anuncia el Reino» (Gutiérrez, 1984, p. 198) $\mathrm{y}$ «la soledad no se opone a la comunión, por el contrario la prepara, nos dispone auténticamente a ella» (Gutiérrez, 1984, p. 130). Esta experiencia espiritual es el pozo del que debe beber toda la Iglesia según Gutiérrez.

\subsection{Jon Sobrino}

El seguimiento de Jesús es la categoría desde la que Sobrino sistematiza la propuesta espiritual que se abre paso en América Latina durante estos años. Un seguimiento que parte del Jesús histórico y de su servicio al Reino: «el seguimiento de Jesús incluye el esfuerzo por identificarnos con sus preocupaciones históricas y con sus posturas y compromisos en medio de realidades de pecado con una intención de liberación» (Estupinán et al., 2013, p. 423). Desde esta categoría aparece una espiritualidad de la cruz que conlleva exigencias en la vida política. El seguimiento nos sitúa en la realidad, produce conductas y comportamientos que tienen implicaciones al interior de la sociedad (Estupiñán et al., 2013), incluso ayuda a entender 
la experiencia del martirio, realidad que vive muy de cerca el pueblo que Sobrino acompaña y que más tarde llegaría a tocar a su propia puerta, en sus hermanos de la Universidad de El Salvador.

Sobrino re-significa la comprensión de la oración, desde el discernimiento, categoría de la espiritualidad clásica. Igualmente, lee la espiritualidad de Jesús y de la liberación en términos de honradez con lo real, que supone reconocer la verdad de las cosas tal como son, pues:

Sin honradez con lo real, las cosas no son ya para nosotros y pierden su carácter sacramental revelatorio, por lo tanto, no puede existir una experiencia de Dios, ni por el lado del objeto (la creación), ni por el lado del sujeto (el corazón entenebrecido). (Sobrino, 1979-1980, p. 63)

Otro elemento que introduce Sobrino en la reflexión sobre la espiritualidad es la fidelidad hacia lo real. Además del reconocimiento de la realidad tal como es, sin manipulación alguna, plantea la exigencia de desmentir su negación - pecado- y alimentar su positividad, fomentando la vida. $\mathrm{Al}$ respecto afirma que "Jesús es fiel a la exigencia de la realidad sin rehuir sus consecuencias, aunque estas le pongan en situación de no poder controlar ya de qué realidad se trata» (Sobrino, 1979-1980, p. 61).

Para finalizar, Sobrino (1985, p. 29) habla de corresponder a y dejarse llevar por el más de lo real, debido a que en la realidad hay algo de promesa y de esperanza que se resiste a ser acallada, a pesar de las circunstancias, y que invita a buscar la plenitud.

\subsection{Segundo Galilea}

La síntesis de Galilea, también elaborada durante la década de los 80 , es un esfuerzo por pensar y vivir una Espiritualidad de la Liberación desde las fuentes de la teología, y teniendo como telón de fondo, la particular situación de los pueblos de América Latina. Su trabajo, recogido en el libro El Camino de la Espiritualidad (1982) propone una renovación espiritual necesaria para responder a los retos de la historia. La espiritualidad ha de ser integralmente liberadora y humanizante, pues: 
Emerge en los lugares de la Iglesia latinoamericana donde se verifica mejor este encuentro que es en el ámbito de los pobres: en los grupos, movimientos apostólicos y comunidades cristianas, donde el Espíritu se manifiesta en los valores de la cultura y religiosidad popular y en las aspiraciones y dinamismos de su liberación. (Galilea, 1982, p. 45)

Por otra parte, esta condición de la espiritualidad es la que hace que la lucha por un mundo mejor, en todo sentido, sea fruto del encuentro con Dios en medio de los más pequeños y haga de la experiencia cristiana algo integral.

Su visión se enfoca en la dimensión encarnadora de la fe, en una re-comprensión de la experiencia de Dios, en la contemplación y en la oración, prendándose así en el Evangelio y orientando su reflexión, desde el seguimiento del Jesús histórico, hacia una relación estrecha con la realidad del pobre:

Un primer acento de la renovación espiritual en el pueblo latinoamericano es la revaloración de Jesús histórico. El segundo acento es el sentido del pobre. Ambos temas se incluyen mutuamente. El Jesús de los Evangelios es inseparable del sentido evangélico del pobre, y este último solo se entiende a partir de la enseńanza y la práctica de Jesús. (Galilea, 1982, p. 45)

Junto con el factor esencial de la espiritualidad cristiana que es su carácter trinitario (Galilea, 1982, p. 49), Galilea también sostiene que la dimensión fundamental de nuestra experiencia espiritual es el seguimiento de Jesús (1982, p. 57). Por último, hay que destacar en la sistematización que ofrece Galilea que el lugar de la conversión es el punto de arranque de la espiritualidad cristiana que supone «la conversión cristiana es la conversión a un Dios inseparable del amor al hermano» (1982, p. 124).

\subsection{Néstor Jaén}

Propone una síntesis como expresión de una vivencia encarnada de la fe en medio de comunidades eclesiales centroamericanas. Su trabajo, además de ser un esfuerzo por ocuparse de la espiritualidad, pretende responder a esas visiones reduccionistas de la Espiritualidad de la Liberación que estaban propagándose velozmente en algunos sectores eclesiales (Jaén, 1987, p. 135). 
Al traer a colación la espiritualidad que se experimenta en las comunidades eclesiales de América Latina el libro de Jaén se refiere, claramente, a la Espiritualidad de la Liberación y a la Espiritualidad Política como dos formas de hablar sobre la misma realidad, pues ambas emergen de una nueva visión de experimentar a Dios en el encuentro con los pobres.

Para Jaén (1987) praxis y espíritu son elementos fundamentales en el origen del movimiento cristiano de liberación y, por ende, de su teología y de su espiritualidad. Pretende evitar a toda costa cualquier viso reduccionista de la espiritualidad, por ello, reconoce el dinamismo liberador explícito en la acción del Espíritu que se hace manifiesto en una praxis liberadora del individuo, de la comunidad y del pueblo. Al respecto afirma:

El ser humano es simultáneamente individuo, comunidad y pueblo [...]. Esta triple dimensión no suele ser enfatizada por los autores espirituales. $\mathrm{Y}$ en consecuencia, es algo muy frecuente caer en reduccionismos muy empobrecedores de la vida de la fe. (Jaén, 1987, p. 29)

En relación con lo establecido anteriormente la espiritualidad liberadora busca integrar las relaciones con Dios, con el prójimo, con el mundo y con uno mismo para evitar los intimismos y los espiritualismos. Está en construcción permanente debido a la exigencia continua de conversión a la que estamos invitados.

\subsection{Pedro Casaldáliga y José María Vigil}

Estos autores, a comienzos de los noventa, desarrollaron un ejercicio de sistematización a partir de dos sentidos básicos de la espiritualidad. El primero, un sentido humano fundamental que tiene como eje la vida, la historia, la realidad social, la praxis y la sabiduría. El segundo, un sentido que referencia el contexto y los rasgos propios de quienes lo experimentan. En el caso de América Latina, es una espiritualidad que promueve la liberación a través de un carácter ético-político.

Convencidos de la necesidad de que la voz de la Espiritualidad Latinoamericana, desde sus diferentes rincones y escenarios, resuene en la reflexión teológica del continente, escriben su clásica obra Espiritualidad de la Liberación (1992). Inmersos en un matiz de diálogo e interacción con 
algunos maestros espirituales, en especial con Juan de la Cruz, Casaldáliga se aproxima desde la poesía a una reflexión que se expresa en el seguimiento de Jesús de Nazaret. Al Hijo del Dios vivo que se hace carne e historia, que asume una realidad conflictiva, que se convierte en un ciudadano de su pueblo y en un miembro más de la humanidad. Otro elemento sobresaliente, es el lugar desde donde se vive la acción del Espíritu cuyo punto de partida y de llegada es la realidad como pieza vital del misterio de la encarnación que se encamina hacia el misterio de la Pascua.

Con su aporte, Vigil introduce un carácter más sistemático a la obra. Recopila, de manera completa y sencilla, la cosecha de avances y elaboraciones en torno a la Espiritualidad, aparecidas hasta ese momento, evidenciando así la fuerza profética que tiene el dinamismo liberador, pues reafirma que lo propio de la Espiritualidad Cristiana se concentra en que es una espiritualidad liberadora (Casaldáliga \& Vigil, 1992, p. 10).

Con el propósito de mostrar el lugar propio de la Espiritualidad de la Liberación, al comienzo se detienen en los conceptos de Espiritualidad y Espíritu, como ejes fundamentales, para resaltar posteriormente las características especiales de la Espiritualidad de la Liberación. Estas características son indisociables al descubrimiento del Jesús histórico, cuya vivencia se realiza desde la encarnación y el reinocentrismo presente en la historia concreta de América Latina. Para Casaldáliga y Vigil «la espiritualidad de la liberación es la espiritualidad de la libertad; porque solamente los libres liberan» (Casaldáliga \& Vigil, 1992, p. 11). Para estos autores es muy clara la necesidad de afianzar la espiritualidad particularmente latinoamericana y subrayar la relación que existe entre la Espiritualidad de la Liberación y la Teología que surge de esta experiencia de Dios en el contexto latinoamericano:

La Liberación tiene su Sociología, su Pedagogía, su Teología. Nombres ilustres, libros cruciales. La Liberación tiene, sobre todo, su Espiritualidad. De la Espiritualidad de la Liberación, vivida diariamente en la pobreza, en el servicio, en la lucha y en el martirio, surgió precisamente la Teología de la Liberación, que ha pensado sistemáticamente toda esa vida y sus motivaciones de fe. (Casaldáliga \& Vigil, 1992, p. 13) 


\section{CONSOLIDACIÓN DE LOS RASGOS DE LA ESPIRITUALIDAD DE LA LIBERACIÓN}

El aporte de estos autores hizo posible identificar algunos matices a partir de los cuales se consolidan los rasgos y sentido de la Espiritualidad de la Liberación, que como espiritualidad teologal responde a la pregunta por el sentido último de la existencia en medio de la realidad y orienta la elección entre el servicio a Dios o a los ídolos que se erigen en el mundo (Sobrino, 1990, p. 508).

Este esfuerzo por encarnar y dar cuenta de dinamismo espiritual en América Latina, es entre otras, una manera de corresponder a la invitación de la Tercera Conferencia General del Episcopado realizada en Puebla al exhortar a la iglesia a reavivar la fe, a que la fe "alimente una espiritualidad capaz de asegurar la dimensión contemplativa, de gratitud frente a Dios y de encuentro poético, sapiencial, con la creación. Fe que sea fuente de alegría popular y motivo de fiesta aun en situaciones de sufrimiento (Puebla, 1979, No. 466).

A continuación se presentan los rasgos más sobresalientes de la Espiritualidad de la Liberación a partir de las obras y los autores estudiados.

\subsection{Experiencia de Dios}

La experiencia de Dios se constituye en el fundamento de la dimensión contemplativa que induce al compromiso (Galilea, 1982), una experiencia de Dios encarnada en la historia, es decir, que:

Estamos llamados a experimentar a Dios no sólo en los momentos de oración [...], sino también en la vida, en la acción, en la naturaleza y en la historia. El Dios de Jesús se revela en el corazón de cada hombre y también en la realidad histórica. (Galilea, 1982, p. 136)

La experiencia de Dios es un «tema vital» (Casaldáliga \& Vigil, 1992, p. 37) junto con el seguimiento de Jesús y la pobreza. Hablar de experiencia de Dios es descubrir que nuestra fe no se limita a escuchar un mensaje sino 
que también consiste en identificar a sus destinatarios, su finalidad y su sentido que está en dar la vida por el Reino; pues la experiencia acontece en el encuentro con Jesús para conocerle, amarle y seguirle: «hay que experimentar a Dios, porque se puede. Porque esta experiencia -de fe, de confianza, de servicio en el servicio a los hermanos- es lo más vital de nuestra propia vida» (Casaldáliga \& Vigil, 1992, p. 40).

En este sentido, el lugar central de la experiencia de Dios está en el encuentro con el hermano (Gutiérrez, 1984, p. 42) puesto que la irrupción del pobre es la irrupción de Dios: punto de partida y eje de esa nueva espiritualidad que invita a una transformación radical para sentir, pensar y vivir como Cristo, quien se hace presente en el marginado y en el oprimido. Una forma particular de ver el mundo: desde el reverso de la historia, desde las víctimas (Jaén, 1987, pp. 86-87) de la opresión y de la marginación.

En el dinamismo del encuentro la experiencia de Dios se vive como «experiencia de acción» (Comblin, 1990, p. 623) que se ilumina desde la Sagrada Escritura como experiencia de libertad, como experiencia de Palabra que denuncia el silencio, como experiencia de comunidad y como experiencia de vida que supera el reino de la muerte en el que ha vivido el pueblo latinoamericano.

Así pues la experiencia de Dios es un rasgo característico de quien opta por la honradez y por ser fiel a lo real, no es meramente el presupuesto para una experiencia espiritual de Dios, sino que es su materia propia e independiente y en la cual acontece la revelación.

\subsection{Conversión}

Es un rasgo distintivo de la Espiritualidad de la Liberación y posibilita el movimiento, la conciencia solidaria, la visibilización de las situaciones de injusticia y de las realidades sociales de pobreza y marginación. La conversión permite dinamizar los procesos de transformación y cambio. Es una ruptura y un "proceso que afecta a la persona y a la sociedad" (Galilea, 1982, p. 129), que implica la cruz y el seguimiento de Jesús más allá del ámbito personal pues: 
Las exigencias sociales de la conversión son inherentes a la naturaleza de la conversión a causa del ideal fraterno que Jesús trajo y por el cual entregó su vida. La experiencia cristiana es experiencia de fraternidad y compromiso por construir la fraternidad entre los hombres. (Galilea, 1982, p. 156)

El encuentro con Dios que provoca la Espiritualidad de la Liberación (Sobrino, 1984) conlleva una exigencia de conversión, de discernimiento y de amor que se gesta en la interioridad del ser humano y que se hace explícita en medio de la comunidad, como una oración de carácter personal y comunitario y, en definitiva, como una praxis liberadora.

\subsection{Oración - Contemplación}

Desde los albores de la Teología de la Liberación y de su espiritualidad la oración, la contemplación y el discernimiento, han sido entendidos en estrecha relación con la acción. Se trata entonces de una correlación que otorga autenticidad al vivir cristiano. No en vano, antes del hablar teológico está el silencio que conlleva un doble dinamismo: la contemplación y la acción. En este sentido:

En la oración se permanece mudo, simplemente nos situamos ante el Señor. Y en la práctica, en cierto sentido, también se calla; porque en el compromiso, en el trabajo diario, no estamos hablando de Dios todo el tiempo; cierto es que vivimos de él, pero no discurriendo sobre él. (Gutiérrez, 1992, p. 17)

La oración es «expresión de fe, de confianza en el Señor, es un acto original y propio del creyente» (Gutiérrez, 1984, p. 166) pues se mueve en el ámbito del amor y la gratuidad. En este encuentro, como en toda experiencia, la experiencia del amor humano lo revela, accedemos al ámbito del Misterio (Gutiérrez, 1992, p. 17). La oración implica escuchar atentamente, hablar y dejar hablar a Dios, es algo connatural al trabajo por el Reino y se hace posible gracias al Espíritu de Dios (Sobrino, 1990, p. 508).

En relación con lo anterior, la oración como silencio y acción, se convierte en una señal de quien se quiere dejar guiar por el Espíritu. Es el 
momento previo a toda expresión posible y soñada sobre Dios y sobre su actuar en la historia.

\subsection{Discernimiento}

El Espíritu es quien orienta el discernimiento con miras a la construcción de un hombre nuevo (Comblin, 1990, p. 624) que se da únicamente en la libertad, y esa libertad consiste en participar de la creatividad de Dios. Lo novedoso está en la posibilidad de crear fraternidad con los otros bajo la moción del Espíritu, acompañados siempre por la oración y transformando todo aquello que vulnera la dignidad del hermano. Solo así se rememora la esperanza y se reviven las aspiraciones hacia el futuro.

El discernimiento es una «búsqueda concreta de la voluntad de Dios» (Sobrino, 1982, p. 209) que supera la simple noción para orientarse hacia la práctica. Sobrino sitúa al discernimiento, partiendo de las urgencias eclesiales del momento, como una posibilidad efectiva y real de reafirmar lo histórico, lo concreto desde el amor según la exigencia paulina.

Discernir es reconocer las huellas de Dios en la historia y percibir en ellas un proyecto vocacional. Particularmente en la experiencia de las comunidades eclesiales de base (Jaén, 1987, p. 75) para las que el discernimiento es una característica distintiva puesto que, de modo especial, requiere de la ayuda del Espíritu para tomar decisiones y construir opciones.

\subsection{Pobreza espiritual}

La pobreza espiritual es sinónimo de infancia espiritual y se comprende como la condición en la que se pone la vida en manos de Dios: el desprendimiento de los bienes es consecuencia de esa pobreza espiritual. Por lo tanto, el pobre de espíritu es el discípulo o seguidor de Cristo, expresamente identificado en las bienaventuranzas de Mateo, con unas actitudes propias: practicar la justicia, ser misericordioso, construir la paz. De ahí que ser pobre de espíritu adquiere sentido, no porque ser pobre sea un ideal, sino porque el discípulo de Cristo opta por la solidaridad, por favorecer a los pobres y por estar siempre de su lado. 
La pobreza espiritual, por esta razón, es una actitud interior, una disposición especial al desprendimiento y a la buena voluntad, de manera que el pobre espiritual no es el carente de bienes materiales sino aquel no se apega a ellos. Así, un rico puede ser un pobre espiritual y un pobre puede ser un rico de corazón (Gutiérrez, 1975, p. 324).

La pobreza espiritual, como actitud interior (Pixley \& Boff, 1986, pp. 170-172), se manifiesta en la vida exterior. Los pobres espirituales no tienen el corazón apegado a las cosas o a los bienes materiales, frente a ellos se comportan en libertad. Les da igual vivir en un palacio o en una casa del común.

\subsection{Santidad política}

Para abordar el concepto de santidad política es indispensable revisar sus componentes por separado. Por santidad entendemos con Sobrino «una realización notable de la fe, de la esperanza y sobre todo, de la caridad y de las virtudes que genera el seguimiento de Jesús» (Sobrino, 1985, p. 99), por política interpretaremos «aquella práctica dirigida a transformar estructuralmente la sociedad en la dirección del reino de Dios, en que se haga justicia a las mayorías pobres y oprimidas y en que éstas encuentren vida y salvación histórica» (Sobrino, 1985, p. 99).

Es entendida como una forma de vida que pretende ser una respuesta a la voluntad de Dios, que remite a una nueva humanidad en donde se entrecruzan la filiación y la fraternidad. En palabras de Sobrino: «el santo político es el que una y otra vez echa mano del ideal del reino de Dios y del Dios del Reino para configurar la historia y su propia práctica» (Sobrino, 1983, p. 340).

Esta categoría permite describir el compromiso cristiano de una promoción humana integral que supera el asistencialismo y que descubre la esencia del seguimiento de Jesús. Esta relación entre santidad y política, para Sobrino, conduce al descubrimiento de un nuevo mediador: el amor político.

El amor político supone reconocer la realidad tal como es y permite conmover para obtener una verdadera eficacia, eficacia que se relaciona 
con los destinatarios de ese amor y con su objeto de acción. No son ellos, los individuos en particular, sino los colectivos, la clase social emergente, el mundo de los pobres y sus estructuras: «para ello debe denunciar la opresión y desenmascarar sus causas estructurales, abogar por sus derechos básicos, humanos, sociales y políticos, propiciar los cambios estructurales 'urgentes y audaces', como decía Pablo VI» (Sobrino, 1985, p. 101).

El santo político de hoy es quien se aproxima a las mayorías pobres y asume las consecuencias de ese acercamiento (Sobrino, 1985, p. 104). Sin embargo, el ámbito político tiene sus propias tentaciones y dificultades porque trae consigo el uso del poder. Estas limitaciones exigen la acción del Espíritu de Dios para ayudar a mantener los ideales. Ese Espíritu es la santidad que aunque parece idealista, es eficaz históricamente (Sobrino, 1985 , p. 105). Finalmente, la praxis de la santidad política permite, al pueblo o al sujeto implicado, decidirse a emprender la lucha por la liberación de manera contundente y le obliga a denunciar cualquier desviación de esa acción política de su verdadero objetivo: el beneficio de las mayorías pobres.

\subsection{Comunidad}

La experiencia comunitaria es un signo de la acción del Espíritu. Si Dios es comunión perijorética, la acción del Espíritu, que es del Padre y del Hijo, posibilita y facilita el hecho comunitario. En América Latina el dinamismo del Espíritu hizo posible la experiencia en las comunidades eclesiales de base (Jaén, 1987, p. 72) dinamizada desde la recepción de los documentos del Concilio Vaticano II y de las Conferencias Episcopales durante las décadas de los años sesenta y setenta.

Las comunidades eclesiales surgían a partir de los imperativos de escucha de la palabra y del discernimiento de la realidad histórica. Además de ser un instrumento de evangelización, plasmaban la acción del Espíritu en su diario vivir. Gustavo Gutiérrez, sensible a esta experiencia vivida al interior de esas comunidades, afirma que la Espiritualidad de la Liberación es una aventura comunitaria porque:

Solo en comunidad podemos escuchar, acoger y anunciar el don y la gracia del Señor, el llamado privilegiado a superar todo lo que rompa la comunión fraterna (opresión, injusticia, marginación, discriminación, etc.), 
porque es al mismo tiempo ruptura con Dios, y a luchar por la implantación de los valores que Jesús anuncia. (1984, p. 198)

Esta experiencia del Espíritu, vivida en comunidad, se da en un contexto de lucha por la liberación (Gutiérrez, 1984, p. 12) en procura del amor y la justicia. Abre el paso a un pueblo que traza su propio camino en el seguimiento de Jesucristo, que:

Implica para todos el compromiso en una misión, para lo cual, como el maestro, es necesario acampar en la historia humana y desde allí dar testimonio del amor del Padre [...] El encuentro con el Señor no queda en los discípulos, la naturaleza misma de ese acontecimiento lleva a la comunicación, al testimonio. (Jaén, 1987, p. 68)

\subsection{Perspectiva mariana}

María se hace presente en todas las espiritualidades cristianas. Ella es la Madre de Dios, la Madre nuestra, es la llena de gracia, la bendita entre todas las mujeres, es esa mujer del pueblo que aparece en el Evangelio. Es esposa de un noble carpintero pobre, es una mujer laica, una mujer humilde, una mujer sencilla, una mujer sufrida que acompañó a Jesús desde Belén hasta el Calvario. Es el modelo perfecto de mujer excepcional en medio de una vida corriente. No es, de manera alguna, una mujer ajena e indiferente ante las inequidades sociales y el carisma profético. ¡No! Ella, en su maravilloso canto del Magnificat, profetiza en contra de los ricos soberbios y clama a favor de los pobres y humildes de corazón (Jaén, 1987, p. 101).

En las Sagradas Escrituras, desde el Antiguo Testamento, las vidas de Miriam, Ana, Rut, Judith y Ester, simbolizan la resistencia de un pueblo cuyas acciones son una revelación de la fuerza de un Dios salvífico. Desde esta perspectiva se entiende a María (Gebara \& Lucchetti, 1990, p. 605) hoy en América Latina como símbolo de un pueblo fiel, una morada particular de Dios, una nueva arca de la Alianza: lugar en donde Dios puede ser encontrado y amado.

En el Nuevo Testamento, especialmente en el Evangelio de Juan, María aparece como la madre de la nueva comunidad de esos hombres y mujeres que siguieron a Jesús porque creyeron en la gloria que manifestó de su Padre. 
Ella es el símbolo, el centro del mensaje de la Salvación, en un pueblo que llevará hasta su plenitud la causa mesiánica (Gebara \& Lucchetti, 1990, p. 607).

María se convierte en vocera de la primera hora de la nueva Iglesia y de un nuevo modo de ser mujer. De ahí que el pueblo latinoamericano, pobre y oprimido, sujeto de la historia y organizado para la liberación, ve en María una aliada de sus clamores: «María es la esperanza, la madre, la protectora, aquella que no abandona a sus hijos» (Gebara \& Lucchetti, 1990, p. 603). Esto explica la consolidación de la devoción mariana y por ello, de la espiritualidad en el pueblo latinoamericano.

\section{EL SENTIDO TEOLÓGICO DE UNA ESPIRITUALIDAD EN CAMINO}

Si bien la primera fase ${ }^{6}$ de la investigación señalaba que el sentido teológico emergía como un dinamismo teologal «en el anhelo de liberación presente en la gran mayoría de pobres que padecían la exclusión y la marginación» (Estupiñán et al., 2013, p. 424). En esta segunda fase, que abarca el período comprendido entre 1979 y 1992, aparece un proceso de fortalecimiento y de profundización de los rasgos ya predominantes, manifiestos en el florecimiento de múltiples publicaciones y trabajos de síntesis a nivel teológico-espiritual. De este modo, es posible comprobar que el sentido teológico no solo se conserva, sino que se reafirma desde la diversidad de expresiones que adquiere esa reflexión sobre la espiritualidad.

Ahora bien, si la consolidación se hizo evidente en las diferentes síntesis elaboradas, es necesario volver nuevamente la mirada hacia ellas, especialmente hacia las categorías de encarnación y seguimiento cuya referencia a la realidad histórica y a la urgencia de liberación contribuyen a la comprensión integral del ser humano.

6 Las expresiones de la Espiritualidad de la Liberación en el período comprendido entre 1968 y 1979. 


\subsection{Encarnación}

La reflexión teológica latinoamericana condujo a un redescubrimiento de las características fundamentales de la vida cristiana (Sobrino, 1985, p. 11), como una lección de los años setenta en la que se destaca la encarnación, que se ubica en el marco del seguimiento de Jesús (Casaldáliga \& Vigil, 1992, p. 132). La referencia directa a la necesidad de encarnación en la realidad latinoamericana, condujo a muchos miembros de comunidades religiosas a establecer un contacto más próximo con los pobres reales, quienes «se convirtieron en el lugar de la vida cristiana" (Sobrino, 1985, p. 11).

Esta forma de vida cristiana, encarnada y solidaria con el pueblo pobre y oprimido, trajo consigo la persecución y, en algunos casos, el martirio y la muerte precipitada. Además, sirvió para identificar el «criterio de verificación de la encarnación y de la práctica del amor» (Sobrino, 1985, p. 12). Ahora bien, la muerte y el martirio son dos realidades con las que tiene que lidiar el amor liberador. Ser consecuente es aceptar que para encontrar la vida hay que perderla ${ }^{7}$ que «nadie tiene mayor amor que el que da la vida por sus amigos» (Sobrino, 1985, p. 53).

Esta invitación a una vida cristiana encarnada desde la realidad Latinoamericana permite comprender que:

Al Dios encarnado, increíblemente cercano a los pobres y oprimidos en el escándalo de la cruz, se accede por afinidad en la encarnación entre los crucificados de la historia, en la persecución, en la entrega de la propia vida con y por ellos. (Sobrino, 1985, p. 53)

La encarnación en medio de la historia real de hombres y mujeres continúa siendo la acción más representativa de la existencia cristiana que no se realiza de una vez y para siempre, sino que implica todo un proceso de la propia vida ${ }^{8}$. Tal como afirma Sobrino, pues «debe ser siempre de nuevo asegurada y conquistada, que no debe ser nunca dada por supuesta y que -en la práctica- con tanta dificultad se realiza» (1985, p. 145).

7 Véase Mc 8,35.

8 La afirmación obedece a que «es toda la vida de Jesús la que es un 'proceso' de encarnación» (Casaldáliga \& Vigil, 1992, p. 133). 
El dinamismo liberador es el cimiento del proceso de encarnación que apunta a la salvación. Más aún, como afirma la instrucción sobre algunos aspectos de la Teología de la Liberación «el Evangelio de Jesucristo es un mensaje de libertad y una fuerza de liberación» (Congregación para la Doctrina de la Fe, 2015). En relación con esto, Casaldáliga \& Vigil (1992) consideran que la Espiritualidad de la Liberación asume:

La procesualidad de la vida humana, su evolución, su crecimiento, sus altibajos, sus tentaciones, sus crisis, sus perplejidades, la rutina y monotonía [...]. Y asume también los procesos históricos de los Pueblos, sus angustias y esperanzas, sus luchas de liberación. (p. 133)

\subsection{Seguimiento de Jesús}

La encarnación nos remite, necesariamente, al seguimiento de Jesús, pues si bien en la vida de Jesús, Dios-Hijo se humanizó, su existencia es el camino perfecto para que el creyente entre en comunión con Dios y pueda recorrer ese mismo camino para entrar en la dinámica del seguimiento. En el seguimiento de Jesús se juega la fe, nuestra fe en él como el Ungido, el Hijo de Dios, puesto que:

No se puede confesar a Dios sin trabajar por su reino; no se puede confesar a Cristo sin el proseguimiento histórico de Jesús. Formulado en los términos que ahora nos interesan: no puede haber vida 'espiritual' sin 'vida' real e histórica; no se puede vivir 'con espíritu' sin que el espíritu se haga 'carne'. (Sobrino, 1985, p. 13)

Más que teorizar sobre el seguimiento, es fundamental apropiarse del mismo. En el compromiso por la liberación, confluyen la encarnación, el seguimiento y el dinamismo liberador. En la investigación queda claro el sentido teológico de la Espiritualidad de la Liberación.

Al respecto, Monseñor Óscar Arnulfo Romero reúne todos los requisitos propuestos por esta dinámica espiritual, ya que encarnó su fe en la realidad salvadoreña siendo honesto, manteniéndose fiel a los anhelos de liberación y asumiendo siempre un compromiso verdadero con el pueblo pobre al que le remitía el Evangelio. Esa dinámica encarnadora le permitió vivir, de 
manera real y elocuente, el seguimiento de Jesús en su decidida lucha por la liberación del pueblo pobre de El Salvador. Su acción, permeada por el Espíritu en su gesta por la justicia, fue absolutamente clara:

Ante un mundo que necesita transformaciones sociales evidentes, ¿̨cómo no le vamos a pedir a los cristianos que encarnen la justicia del cristianismo, que la vivan en sus hogares y en su vida, que traten de ser agentes de cambio, que traten de ser hombres nuevos?... Nada hay tan importante para la Iglesia como la vida humana... sobre todo de los pobres y oprimidos... Me alegro, hermanos, de que nuestra Iglesia sea perseguida por tratar de encarnarse en el interés de los pobres... Sería triste que en una patria donde se está asesinando tan horrorosamente no contáramos entre las víctimas también a los sacerdotes. Son el testimonio de una Iglesia encarnada en los problemas del pueblo [...]. Mi posición de pastor me obliga a ser solidario con todo el que sufre y a apoyar todo esfuerzo por la dignidad de los hombres... Mi muerte, si es aceptada por Dios, sea por la liberación de mi pueblo y como un testimonio de esperanza en el futuro. (Romero, 2015)

\section{CONCLUSIÓN}

La reflexión realizada sobre este período de la historia de la espiritualidad en América Latina pretendió mostrar el esfuerzo de los diversos autores por contribuir a la transformación de la realidad de pobreza y marginación y consolidar la experiencia espiritual en las comunidades eclesiales de nuestro continente. El ejercicio sistemático de integración de los diferentes elementos implicados en la experiencia espiritual, que abarcan la totalidad de la persona y de sus relaciones, posibilita entender mejor ese dinamismo liberador que se transforma desde la presencia y la acción del Espíritu. No en vano afirma la Escritura: «porque el Señor es el Espíritu; y donde está el Espíritu del Señor, allí hay libertad» (2 Cor, 3,17).

Al finalizar esta investigación se ha podido confirmar que en los cimientos, tanto de la Espiritualidad como de la Teología de la Liberación, existe una manera particular de experienciar la relación con Dios a través del encuentro con los pobres y con sus anhelos de liberación. Al estudiar las formas que asume la espiritualidad, la riqueza de la diversidad de sus 
rasgos, se hace evidente que en América Latina esta propuesta espiritual se consolidó en torno al dinamismo liberador, a la centralidad en la Escritura y a la reflexión sobre el misterio de Dios a partir del seguimiento de Jesucristo para anunciar el amor gratuito de Dios Padre por todos y cada uno de los hombres (Gutiérrez, 1984, pp. 181-182).

El sentido teológico que surge de los rasgos de la espiritualidad recobra vida en la apropiación de ese anhelo de liberación que emerge de la honestidad, dentro de una realidad permeada por la injusta pobreza y la marginación, en situaciones que ponen en riesgo toda vida humana y provocan la muerte precipitada de muchas personas. Esa realidad tangible invita a un compromiso de fidelidad consigo mismo, desde una praxis liberadora capaz de manifestar más de lo real, induce y recrea la esperanza latente en la Escritura: "pero nosotros, conforme a la promesa de Dios, esperamos unos nuevos cielos y una nueva tierra, en los que habite la justicia» $(2 \mathrm{Pe}, 3,13)$.

Esta apropiación del anhelo de liberación, que implica la totalidad de la vida y que se manifiesta en la triple dinámica de honestidad, fidelidad y apertura a lo real, pone en primer plano el seguimiento de Jesús y la acción reveladora del Espíritu que actualiza el misterio de la Encarnación, misterio desde el cual debe emerger un hombre nuevo, a imagen de Jesús, el Cristo. Además, al dirigir la mirada sobre nuestra realidad presente en estos inicios de siglo y de milenio, es posible constatar que si bien las condiciones sociales, políticas, económicas, religiosas y culturales no son las mismas de la década de los 80, la realidad de pobreza y marginación sigue estando presente, agudizada ahora por fenómenos como el desplazamiento forzado que se alimenta de la violencia y la corrupción generalizada. Esta situación hace aún vigente el anhelo de liberación, que será fuente de inspiración para los creyentes que busquen ser fieles a la acción del Espíritu, y que apuesten por un seguimiento real de Jesucristo en medio de la realidad histórica.

\section{LISTA DE REFERENCIAS}

Casaldáliga, P., \& Vigil, J. M. (1992). Espiritualidad de la Liberación. Santander: Sal Tarrae. 
El sentido teológico de una espiritualidad en camino

Comblin, J. (1990). Espíritu Santo. En L. Ellacuría, \& J. Sobrino, Mysterium Liberationis I. "Conceptos fundamentales de la teología de la liberación" (pp. 619-642). Madrid: Trotta.

CELAM. (1979) III Conferencia General del Episcopado Latinoamericano. Puebla.

Obtenido de http://www.celam.org/doc_conferencias/Documento_Conclusivo_ Puebla.pdf

Congregación para la Doctrina de la Fe. (25 de junio de 2015). Instrucciones sobre algunos aspectos de la "Teología de la Liberación". Obtenido de http:/www. vatican.va/roman_curia/congregations/cfaith/documents/rc_con_cfaith_ doc_19840806_theology- liberation_sp.html

Ellacuría, I., \& Sobrino, J. (1990). Mysterium Liberationis I. "Conceptos fundamentales de la teología de la liberación". Madrid: Trotta.

Estupiñán, M. Á., Hoyos Camacho, A. A., Navarro Sánchez, R. E., Rodríguez Osorio, H., Solano Pinzón, O., \& Zurek Lequerica, J. A. (2013). El despertar de la Espiritualidad de la Liberación: evolución de sus expresiones desde Medellín hasta Puebla. Revista Cuestiones Teológicas. Vol. 40. N. 94, 405-431.

Galilea, S. (1982). El camino de la Espiritualidad. Bogotá: Paulinas.

Gebara, I., \& Lucchetti, M. C. (1990). María. En I. Ellacuría, \& J. Sobrino, Mysterium Liberationis I. "Conceptos Fundamentales de la Teología de la Liberación” (págs. 601-619). Madrid: Trotta.

Gutiérrez, G. (1975). Teología de la Liberación. Perspectivas. Salamanca: Sígueme.

Gutiérrez, G. (1984). Beber en su propio pozo. Salamanca: Sígueme.

Gutiérrez, G. (1992). El Dios de la Vida. Salamanca: Sígueme.

Jaén, N. (1987). Hacia una Espiritualidad de la Liberación. Santander: Sal Terrae.

Lepre, M. L. (Marzo de 2008). Reformas neoliberales en América Latina: Argentina y Venezuela. Las reformas de los presidentes Carlos S. Menem y Carlos A. Pérez en perspectiva comparada. Obtenido de Revista de Ciencia Política. N. 3: http://www.revcienciapolitica.com.ar/num3art4.php

Maccise, C. (1987). El problema es la Teología de la liberación. Bogotá: Paulinas.

Olivieri, M. (1984). Orígenes y evolución de la presencia militar en América Latina. Revista de Estudios Políticos. N. 42, 163-188.

Pixley, J., \& Boff, L. (1986). Opción por los pobres. Madrid: Paulinas. 
Romero, A. (25 de junio de 2015). Homilía primer domingo de adviento, 3 de diciembre de 1978. Obtenido de http://servicioskoinonia.org/romero/ homilias/B/781203.htm

Sobrino, J. (1979-1980). Espiritualidad de Jesús y de la Liberación. Revista Christus. N. 529-530.

Sobrino, J. (1982). Jesús en América Latina, su significado para la fe y la teología. Santander: Sal Terrae.

Sobrino, J. (1983). Perfil de una santidad política. Concilium 183, 335-344.

Sobrino, J. (1984). Espiritualidad y liberación. Santander: Sal Terrae.

Sobrino, J. (1985). Liberación con Espiritu. Apuntes para una nueva espiritualidad. Santander: Sal Terrae.

Sobrino, J. (1990). Centralidad del reino de Dios en la Teología de la Liberación. En I. Ellacuría, \& J. Sobrino, Mysterium Liberationis I. "Conceptos fundamentales de la teología de la liberación". Madrid: Trotta. 